\title{
A Summary of Research on the Reform of the Training Mode of Engineering Cost Professionals in Applied Undergraduate Universities
}

\author{
Fangyan $\mathrm{Yu}^{1, \mathrm{a}}$, Liang $\mathrm{Chen}^{1, \mathrm{~b}}$ and $\mathrm{Na}$ Xiong ${ }^{1, \mathrm{c}}$
}

\author{
${ }^{1}$ School of Engineering Management, Nanchang Institute of Technology, Nanchang, China

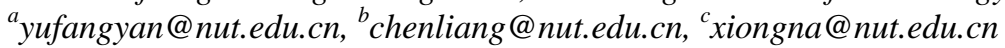

\begin{abstract}
The engineering cost specialty mainly trains students' control over project cost and the budgetary budget calculation ability of the project. This paper summarizes the research results of scholars such as Chen Shuzhen, Liao Junyan, Guo Xu, Zhou Hongli, Zhou Yazhen, Yan Peng, Gao Wei and Liu Xuxia. The training goal of engineering cost students is to discuss the reform and practice of the professional mechanics course in applied undergraduate colleges. From the aspects of teaching content, teaching methods and practice links, we try to find some students interested and knowledge points easy to master way.
\end{abstract}

Keywords: applied, engineering cost, teaching

\section{INTRODUCTION}

As the society changes the demand for talents, the Ministry of Education divides undergraduate colleges into two categories: research and application. Applied undergraduate and research-based undergraduates have distinctly different differences in teaching plans, curriculum settings, teaching content, teaching methods, and teaching effects. Applied undergraduate education belongs to a higher level of technical education, which mainly cultivates high-tech applied talents that meet the needs of the first line of production, construction, management and service[3]..

With the continuous improvement of China's economic level, the construction industry is constantly developing towards maturity. The project cost is an important part of the construction industry. It is mainly for the accounting of costs, profits and taxes in construction projects. It i s an important basis for ensuring the rationality of construction investment and has high technical requirements. However, in the current professional teaching of engineering cost, there are problems such as unclear teaching objectives and unreasonable positioning, which seriously affects the teaching level of the cost-based profession and cannot meet the talent demand in the current industry. Therefore, the teaching reform of engineering cost specialty is imperative[4].

\section{TEACHING STATUS OF ENGINEERING COST TEACHING IN APPLIED UNDERGRADUATE COLLEGES}

\subsection{The Curriculum is More Conservative}

With the development of society, some new educational concepts and educational methods are constantly appearing. If the project cost teaching is not updated in time, only the original teaching mode will remain, the teaching level will not be improved, and the knowledge learned by students will be difficult to adapt to the society. The demand is not conducive to the mastery of students' skills. It is difficult for students to adapt to changes in society and professional requirements, and there is no competitive advantage in society. If students can't learn more useful knowledge through learning, then they should not achieve the effect of education. Therefore, it is necessary to improve the teaching of engineering cost.

\subsection{Teaching Mode is More Traditional}

In the teaching of engineering cost, the teaching mode is mainly based on the teacher's single lecture, and the students are in a passive position in teaching. In the teaching process, the teacher only teaches the knowledge and imposes the knowledge on the students. The students simply memorize the knowledge, do not actively understand the knowledge, do not integrate and digest, and make the knowledge become their own. This teaching mode does not meet the requirements of the new curriculum reform, and students do not occupy a dominant position in teaching. Under this teaching mode, it is difficult for students to truly learn knowledge and learning methods, and it will also restrict the improvement of teaching level. Therefore, without changing this traditional teaching mode, it is difficult to improve the teaching cost of engineering[2]..

\subsection{Lack of Teaching Practice}

In the current engineering cost teaching, practical teaching is relatively lacking, and theoretical knowledge and practice are not connected. Teachers only explain pure theoretical knowledge. In the process of teaching, students are limited by various conditions and cannot conduct on-the-spot investigations. Field visits are very important for engineering cost teaching and are the basis of teaching. Lack of practical teaching will make it difficult for students to apply their knowledge to practice. It is difficult to deepen their understanding of knowledge, and their impression of 
knowledge will not be profound. In addition, students will have poor hands-on ability and lack practical ability in their work[3].

\subsection{The Teaching Evaluation Mechanism is not Perfect}

Due to the fact that many schools do not pay much attention to the evaluation mechanism, the school's implementation of the evaluation mechanism is not in place. This leads to the students' learning in the boring classroom, which makes students lose interest in the study of engineering cost professional knowledge. I have my own thoughts. Under the premise of quality education, students should be regarded as the main body of the classroom, paying attention to the design of teaching plan from the characteristics of physical development and acceptance of students, and strive to effectively improve each student. In this case, it is particularly important to establish a classroom evaluation mechanism. It is an indispensable part of a complete classroom and an important test for efficient classroom construction[5]

\section{REFORM IDEAS FOR THE TRAINING MODE OF ENGINEERING COST PROFESSIONALS IN APPLIED UNDERGRADUATE COLLEGES}

\subsection{Reform Teaching Methods and Means}

As we all know, the courses of engineering cost are diverse, and the key knowledge and framework of each course have different characteristics. This requires teachers to combine their characteristics, appropriately change the teaching mode, and choose the most appropriate teaching methods, such as lecture s, case studies, demonstrations, classroom training, etc., so that students can participate more in the classroom, using teacher-student interaction, grouping Interesting teaching methods such as discussion and on-site operation replace the old teaching mode, stimulate students' innovative thinking and enhance the interest in learning in professional courses. At the same time, it is also necessary to focus on the promotion of teachers' level and accelerate the construction of the "double-skilled" faculty and teaching team for industrial cost.

\subsection{Transforming Teaching Concepts and Optimizing Professional Curriculum}

It is very important to establish a correct concept in the process of learning project cost. The professional concept determines the direction of talent training. Therefore, the prerequisite for improving the teaching level is to change the concept of education. In the curriculum setting, the school should focus on cultivating students' application ability. Application ability is a prerequisite for all abilities. In order to implementing this concept into education, rationally and effectively adjusting the professional curriculum, and constantly improving the curriculum materials according to the needs of the social market, so that the students will have solid basic knowledge, excellent professional skills and good ideology. Practice is also very important. The most important point in the concept of cultivating innovative talents is to combine practice, because students can not only stay in the textbooks, throw away the theory of the whole brain, and must be effective in practice, and all innovations are easy to happen in the case of personal practice, rather than imagination. Foreign experience has taught us that the practice time of engineering cost courses should not be less than 800 hours, so it can be seen how important practice is in the cultivation of engineering talents. In summary, we can know that the first step in cultivating engineering cost professionals is to clarify the concept and increase the proportion of practical teaching, so that students can gradually break away from the shackles of textbooks, seriously think in practice, and truly integrate knowledge points into practice. Go to school and use it. The second step is to follow the trend and update the teaching materials in time. The engineering cost profession needs to keep an eye on the situation and keep pace with the society. If the teaching materials are implemented, the concepts learned by the students are old and new, which is equivalent to the disconnection between education and society, which directly leads to the low quality of talent training. If the content of the textbook cannot be applied to practice, then the course completely loses the meaning of learning. However, the gradual lag of social development is an inevitable problem. Therefore, the Ministry of Education must begin to pay attention to it and timely revise the new version of the textbook. In addition, teachers can be flexible, not limited to teaching materials, and only use it as an auxiliary tool. You can organize and organize your own knowledge and impart new knowledge to students[1].

\subsection{Build a Teaching Mode of "Teaching and Doing Integration"}

Teachers themselves should first learn and accumulate teaching materials, use demonstrations, explanations and other methods to impart knowledge in teaching, and require students to test what they have learned in practice and obtain new theoretical knowledge from practice. According to the profession al characteristics of project cost, the project teaching method is mainly adopted. For example, the construction engineering measurement and pricing course, the teaching focus of this course is to require students to master the determination of project cost under the quota pricing and list pricing model, and to build a teaching, learning and integration teaching environment with typical projects as the carrier. In the course, a moderately difficult construction project is selected as a case. The project is equipped with corresponding construction drawings, construction organization design, etc., and requires students to complete the work of determining the project cost of the project in addition to the theoretical knowledge. Integrating the "small case" into a complete project construction process enables students to integrate knowledge and apply it reasonably and effectively to the cost management of the entire project. For example, in the core curriculum setting, through the complete simulation of the specific case of 
" $\times \times$ engineering", students can master the professional knowledge required in different job environments during the learning process[3]..

\subsection{Re-education Cooperation}

We learn to use it. The school's curriculum is designed to find better jobs, so education must be closely linked to society. Therefore, in the school stage to create a direct facing society teaching system attaches great importance to directly integrate the social concept in the curriculum, curriculum content, according to the needs to develop students' abilities, targeted production and learning. In the future, we need to establish such a system to realize the teaching of simulation work, so that students can experience the fun of pre-job training in learning, find problems and solve problems from actual work, and carry out serious summarization analysis and reflection, and work in society. When you are in trouble, you won't be at a loss. The school actively establishes cooperative relations with enterprises and establishes a stable and reasonable training and practice base, so that students have the opportunity to carry out practical operations, which can fundamentally improve students' comprehensive ability. At the same time, in a simulated environment, students can learn how to communicate, get along with their work partners, and make progress together.

\subsection{Expand Professional Practice Teaching}

With the development of economic globalization, the country's requirements for comprehensive talents are constantly rising. This requires that institutions expand their practical teaching and further enhance their hands-on knowledge to gain a deeper understanding of the knowledge they have learned. First of all, teachers are required to pass the teaching so that students can fully understand the professional knowledge in the classroom, make full use of the engineering cost training laboratory, and let the students learn more and practice more, and master the professional skills of engineering cost. In addition, teachers should also organize students to conduct on-the-spot investigations, go to the construction site for cognitive learning, let students familiar with their work environment in advance, understand the entire workflow, and have an overall understanding of their majors, so that they can The work lays a solid foundation so that it can be more quickly involved in the work.

\subsection{Continuously Improve the Construction of the Teaching Staff in Teaching}

The level of teachers directly affects the quality of classroom teaching, and the teacher team directly affects the development of the entire school. Therefore, in the teaching reform, we must pay attention to the cultivation and improvement of the teaching staff. From the current teaching situation, teachers have rich teaching experience, but the lack of practical operation ability is not conducive to the improvement of students' practical ability. Therefore, from the perspective of teachers, we must correctly understand our own shortcomings in teaching, clarify our own improvement direction, strengthen the exploration and research of practice, and improve our own practice level. From the perspective of the school, it is necessary to actively create conditions for teachers to give them the opportunity to go out of the school and enter the construction industry to understand the actual situation of the current project cost, such as creating a training base, implementing school- enterprise cooperation, and implementing dual-integration. Let teachers have enough practical experience to promote the quality of teaching.

\subsection{Innovation in Assessment Methods}

The assessment takes a random approach, and each student operates one of them. The teacher conducts a review on the spot and finds that the error is corrected immediately. At the same time, it is necessary to ask questions in a timely manner to encourage students to think. This can not only play a role in assessing and testing students' ability, but also enhance students' hands-on ability. It can also enhance teacher-student interaction and improve students' enthusiasm for participating in the classroom. The teacher records the situation and training of each student's knowledge on the spot, and forms part of the course scores as a normal assessment score, so as to improve the students' selfconsciousness and promote the learning effect. Second, focus on the reform of the curriculum performance assessment. The centralized practice curriculum assessment includes professional quality $(10 \%)$, training results and progress $(50 \%)$, and training report (report score, $40 \%)$. The results and progress of the training are based on on- site scoring and group assessment. After each group of students has done it, they will be assessed and scored according to the group, and the scores will be taken as part of the course assessment results, so as to improve students' attention to the usual assessment. The third is the radiation internship evaluation reform. After the graduation internship, the student's grades are assessed by the evaluation team established by the company, department or professional teaching and research section. Corporate evaluation accounted for $50 \%$, instructor scores accounted for $30 \%$, and assessment team scores accounted for $20 \%$.

\section{SUMMARY}

In the construction cost teaching, we should always focus on the needs of the current industry, improve students' practical ability, optimize the teaching curriculum and teaching content, improve the teaching staff, improve the teaching quality, and then truly cultivate the engineering cost talents needed by the construction industry.

\section{REFERENCES}

[1] Liao Junyan. Research on Integrated Teaching Reform Based on Engineering Cost Specialty. Good Day (late). 2017, Issue 9.

[2] Zhou Hongli. On the strategy of teaching reform of 
engineering cost specialty. Modern vocational education·Higher vocational college.2017The nine year period.

[3] Zhou Yazhen. Reform and Practice of Applied Mechanics Course for Applied Undergraduate Engineering Cost. Curriculum Education Research·New Teacher Teaching. 2016-23.

[4] Gao Wei. Analysis of engineering cost teaching reform and talent training measures. Science and wealth. 201732.

[5] Liu Xuxia. Analysis of Teaching Cost Reform and Talent Cultivation Measures in Urban Construction Costs. Urban Tutoring, The Second Half of the Month. 2017, Issue 6. 